\title{
INTRODUCTION TO FLAME RETARDANCY AND POLYMER FLAMMABILITY
}

\author{
Sergei V. LeVChiK \\ Supresta U.S. LLC, Ardsley, New York
}

\subsection{INTRODUCTION}

Together with numerous advantages that synthetic polymeric materials provide to society in everyday life, there is one obvious disadvantage related to the high flammability of many synthetic polymers. Polymers are used in manufacturing not only bulk parts but also films, fibers, coatings, and foams, and these thin objects are even more combustible than molded parts.

Fire hazard is a combination of factors, including ignitability, ease of extinction, flammability of the volatile products generated, amount of heat released on burning, rate of heat release, flame spread, smoke obscuration, and smoke toxicity, as well as the fire scenario. ${ }^{1-3}$ Fire fatalities are usually reported as resulting from the lethal atmosphere generated by fires. Carbon monoxide concentrations measured in real fires can reach up to $7500 \mathrm{ppm},{ }^{4}$ which would probably result in a loss of consciousness in 4 minutes. ${ }^{3}$ Other components of acute toxicity found in real fires play a secondary role: Hydrogen cyanide was measured at levels between 5 and $75 \mathrm{ppm}$, and for irritants such as hydrogen chloride and acrolein, 1 to 280 and 0.3 to $15 \mathrm{ppm}$ were found, respectively. ${ }^{4}$

A recent statistical study covering almost 5000 fatalities showed that the vast majority of fire deaths are attributable to carbon monoxide poisoning, which results in lethality at concentrations much lower than believed previously. ${ }^{5}$ Moreover, the same study showed that blood carbon monoxide loadings in fire

Flame Retardant Polymer Nanocomposites, edited by Alexander B. Morgan and Charles A. Wilkie Copyright @ 2007 John Wiley \& Sons, Inc. 
victims did not change significantly with the advent of synthetic polymers. Carbon monoxide yields (but not concentrations) in big fires are almost independent of the chemical composition of the material burning. ${ }^{6}$ There is evidence suggesting ${ }^{7}$ that there may be longer-term effects from exposure to fire atmospheres that are currently not completely understood.

According to fire statistics, more than 12 million fires break out every year in the United States, Europe, Russia, and China, killing some 166,000 people and injuring several hundreds of thousands. Although calculating the direct worldwide losses and costs of fire is difficult, $\$ 500$ million is an estimate based on some national data. ${ }^{8}$ Despite the increased use of synthetic polymers, U.S. residential fire deaths have declined steadily over the years, from about 6000 in 1977 to about 3500 in 1993, even though the population has increased. ${ }^{9}$ Although fire problems are less severe now, U.S. fire casualties are still higher than in most developed nations. ${ }^{10}$ The decrease in the rate of casualties is a result of many factors, including better design of appliances, electronic equipment, cars, heating equipment, houses, and so on, and ending with changes in the habits of people, such as a drop in the smoking population. The role of flame retardant polymeric materials is also a very important contributor.

In 1988, the National Bureau of Standards [now the National Institute of Standards and Technology (NIST)] ran room combustion tests comparing flame retardant with non-flame retardant plastics used in printed wiring boards, television set and business machine enclosures, cables, and upholstered furniture. ${ }^{11}$ The results showed that flame retardant materials allow more than a 15-fold longer escape time, $75 \%$ less heat release, significantly less smoke, and a lower concentration of toxic gases. Fire retardants decrease toxicity in fires. The effect is due to a decrease in the amount of burning material. ${ }^{1}$

Statistical analysis shows that the fire fatality rate in the UK is much lower than that in the United States for fires where upholstered furniture is the item first ignited. The decrease in fire fatalities per capita in the UK was very rapid during the first decade following passage of UK fire safety regulations on upholstery, and is continuing. The U.S. fire fatality rate for the same types of fires has been decreasing much more slowly. ${ }^{12}$ The Consumer Products Safety Council (CPSC) in the United States is in the final stage of introducing federal standards for upholstered furniture and mattresses, which should increase fire safety in homes in the United States and bring them into line with the UK.

In 1998, the fire safety of television sets and computer monitors manufactured in various countries was studied by a group of flame retardant experts associated with the European Chemical Industry Council. Various ignition sources were utilized, from simulation of a household candle to a trash basket full of paper. The results showed that TV sets purchased in Germany and the Nordic countries ignited easily, even with the smallest ignition source. Normally, these sets did not contain any flame retardant, in order to pass "green" labeling, or contained minimal amounts of flame retardant, to meet the European IEC 60065 test. In contrast, TV sets purchased in the United States or Japan, which were 
designed to meet UL-1410 or UL-1950 (analogous to IEC 60950) tests, were self-extinguishing even after exposure to a more severe ignition source.

It is clear that flame retardants are an important part of polymer formulations for applications in which polymers have a significant chance of being exposed to an ignition source (electrical and electronic goods), where polymers are easy ignitable (upholstered furniture), or where fast spread of a fire may cause serious problems (associated with building materials and transportation) when evacuating people. This chapter provides a short introduction to the principles of polymer combustion and a short overview of the mechanisms of action of the major classes of commercial flame retardants. Although intended to be especially useful for people new to these topics, experts may also find some new information.

\subsection{POLYMER COMBUSTION AND TESTING}

In many respects the combustion of polymers is similar to the combustion of many other solid materials; however, the tendency of polymers to spread flame away from a fire source is critical because many polymers melt and tend to produce flammable drips or flow. Therefore, it is always important to test the combustability of polymeric products under conditions close to those of the final applications or even in assembly with other materials. For example, flame spread can be measured in both the vertical and horizontal positions, but for almost all plastic materials the vertical test is more severe than the horizontal. ${ }^{11}$

\subsubsection{Laboratory Flammability Tests}

Flammability of polymers is assessed primarily through ignitability, flame spread, and heat release. Depending on the application of the polymeric material, one or more of these flammability criteria should be measured in appropriate flammability tests. Numerous flammability tests are known and are performed either on representative samples or on an assembled product. Tests can be small, intermediate, or full scale. Although similar trends in the rating of materials can be found based on small- and large-scale tests, in general there is no direct correlation between these tests.

International and national standards have been developed based on various flammability tests, and they are reviewed elsewhere. ${ }^{13}$ Some relatively simple and inexpensive laboratory tests have found broad application. These tests are used primarily in industrial laboratories for screening of materials during product development or quality control, or in the academic community for studies of polymer flammability. In this chapter we describe some of the commonly used laboratory test methods.

Underwriters' Laboratories UL-94 test is designed to assess the "flammability of plastic materials for parts in devices and appliances." The test measures ignitability and flame spread of polymeric materials exposed to a small flame. It is accepted for standardization in many countries and also internationally. Five 
classifications are included in this test, but we introduce only the V-0, V-1, and $\mathrm{V}-2$ classifications, because they are cited most often in the flame retardant literature. To assess this classification, a bar shape specimen of plastic $120 \times 13 \mathrm{~mm}$ is positioned vertically and held from the top. Depending on the intended use of the plastic, bars may be $3.2,1.6$, or $0.8 \mathrm{~mm}$ thick. Thinner specimens are usually more flammable. Some surgical cotton is placed $300 \mathrm{~mm}$ below the specimen to detect combustible drips that will ignite the cotton. A Bunsen burner flame (ca. $19 \mathrm{~mm}$ high; calibrated) is applied to the specimen twice (10 s each). After each application the time of self-sustained combustion is recorded. A second application of the flame follows immediately after self-extinguishment of the specimen in the first application. A V-0 classification is given to material that is extinguished in less than $10 \mathrm{~s}$ after any flame application. The mean combustion time for the five specimens tested (10 flame applications) should not exceed $5 \mathrm{~s}$, and no combustible drips can be observed. A V-1 classification is received by a sample with maximum combustion time $<50 \mathrm{~s}$ and mean combustion time for five specimens $<25 \mathrm{~s}$. No combustible drips should be observed. The sample is classified V-2 if it satisfies the combustion time criteria of V-1, but flammable drips igniting the cotton are allowed.

Another test commonly used in laboratory practice is the limiting oxygen index (LOI) test. This method has been included in some national and international standards (e.g., ASTM D2863 and ISO 4589). The specimen size and shape is not strictly specified in the LOI test, but bars of about $100 \times 65 \times 3 \mathrm{~mm}$ are generally used when testing rigid plastics. The specimen is positioned vertically in a glass chimney and is held from the bottom. The chimney is purged continuously with a mixture of nitrogen and oxygen. The flame of a Bunsen burner is applied to the top of the specimen until the entire surface is ignited. If the specimen did not ignite after $30 \mathrm{~s}$, the concentration of oxygen is increased. Ideally, the specimen should show stable candlelike combustion. If the specimen continues burning more than $3 \mathrm{~min}$ after removal of the ignition source or if more than $5 \mathrm{~cm}$ of the length of the sample is consumed, a new specimen should be installed and tested at a lower oxygen concentration. The LOI value is the limiting concentration of oxygen at which the sample tested self-extinguishes in less than 3 min with less than $5 \mathrm{~cm}$ of the material consumed. The LOI test does not represent a real fire scenario, but it is good as a screening tool because it gives a numerical value instead of a discrete classification (e.g., V-0, V-1, V-2).

The cone calorimeter test is a bench-scale (medium-sized) test developed at NIST $^{14}$ which quickly gained popularity in the academic community as well as for standardization purposes (e.g., ISO 5660-1, ASTM E-1354). It is also used as a tool for fire protection engineering because it allows prediction of large-scale test results. A cone calorimeter measures consumption of oxygen from a burning sample $100 \times 100 \mathrm{~mm}$ in area and up to $50 \mathrm{~mm}$ thick. The heat release is calculated from the oxygen consumption data. The specimen is exposed to a constant heat flux from a conical-shaped irradiation source, which serves to simulate a variety of fire scenarios. The combustion is initiated by a small sparking igniter, which ignites gases evolved from the heated specimen. In addition to the heat 
release rate, the cone calorimeter apparatus can monitor time to ignition, weight loss of a sample during combustion, rate of smoke generation, carbon monoxide, carbon dioxide, and optionally, some corrosive gases, such as $\mathrm{HCl}$ and $\mathrm{HBr}$.

\subsubsection{Polymer Combustion}

All polymer fires start with an ignition event, where a source of heat comes into contact with a fuel generated by the heating of the polymer. This event initiates a flow of flammable degradation products, which react with oxygen from the air to produce a flame and heat. Some of the heat is transferred back to the surface of the fuel, maintaining the flow of flammable volatile degradation products. ${ }^{3}$ Low ignitability of the polymers is the first line of defense against fire. Although all organic polymers do ignite, the higher the temperature that a material has to reach before it ignites, the safer it is. For most materials, the ignition temperature is in the range 275 to $475^{\circ} \mathrm{C}$. Ignitability is assessed via time to ignition or minimum heat input for ignition. Fire performance improves if either of these increases. ${ }^{1,15}$

Ignitability depends to a large extent on how quickly the surface can be raised to the ignition temperature. Special consideration has to be given to polymers that melt before thermal decomposition. Usually, at a low heat exposure, melting precedes ignition and the polymer can flow or drip, removing heat from the surface. This phenomenon is beneficial for flame retardancy of uncharrable polymers. On the other hand, at a higher heat exposure, ignition may occur before the surface is heated to sufficient depth for the melted material to flow, and such polymers may ignite relatively easy.

Polymeric foamed materials are very specific in terms of ignitability and flame spread. It has been shown that differences in the surface area of foamed polymers and cell size have a larger effect on flammability than do density or differences in chemical structure. ${ }^{16}$ The chemical structure, of course, may dictate the surface area or porosity in the formation of foam. For example, flexible polyurethane foams can be ignited by a smoldering cigarette. A textile material normally used to enclose the foam, as is common in upholstered furniture and mattresses, actually helps ignition if suitable flame retardant-treated textiles are not used.

The possibility of extinguishing a polymer flame depends on the mechanism of thermal decomposition of the polymer. Whereas ignition of a polymer correlates primarily with the initial temperature of decomposition, steady combustion is related to the tendency of the polymer to yield a char, which is produced at the expense of combustible volatile fragments. Therefore, the dependence of steady combustion on the amount of char seems to be simple, and in an early study it was established that the oxygen index shows a very good correlation with the char yield. ${ }^{17}$ In reality, char also serves as a physical barrier for heat flux from the flame to the polymer surface, as well as a diffusion barrier for gas transport to the flame. ${ }^{18}$ Therefore, the contribution of the char can be more significant than is expected from a simple reduction in combustible gases.

Four general mechanisms are important for thermal decomposition of polymers: (1) random chain scission, in which the polymer backbone is randomly split 
into smaller fragments; (2) chain-end scission, in which the polymer depolymerizes from the chain ends; (3) elimination of pendant groups without breaking of the backbone; and (4) cross-linking. ${ }^{19}$ Only a few polymers decompose predominantly through one mechanism; in many cases a combination of two or more mechanisms is in effect. For example, polyethylene and polypropylene tend primarily to decompose via random chain scission, which in the case of polyethylene is also accompanied by some cross-linking. Poly(methyl methacrylate) and polystyrene tend to depolymerize, poly(vinyl chloride) primarily undergoes elimination of pendant groups (dehydrochlorination), and polyacrylonitrile cross-links. In terms of flammability, random scission and depolymerization polymers are usually more flammable than polymers that cross-link or remove pendant groups. Cross-linking ${ }^{20}$ leads to precursors of char and as a result, to lower flammability. Elimination of pendant groups results in double bonds, which can also give cross-links or lead to aromatization.

In general, polymers with aromatic or heterocyclic groups in the main chain are less combustible than polymers with an aliphatic backbone. ${ }^{21}$ Polymers with short flexible linkages between aromatic rings tend to cross-link and char. These polymers are thermally stable and show relatively good flame retardancy. For example, bisphenol A-based polycarbonate, phenol formaldehyde resins, and polyimides are self-extinguishing and show either a V-2 or V-1 rating in the UL94 test. On the other hand, polymers with relatively long flexible (aliphatic) linkages are still relatively combustible despite aromatics in the backbone. Examples of these polymers are poly(ethylene terephthalate), poly(butylene terephthalate), polyurethanes, and bisphenol A-based epoxy resin.

Charring of polymers proceeds through various stages: (1) cross-linking, (2) aromatization, (3) fusion of aromatics, and (4) graphitization. ${ }^{18}$ The ability of a polymer to perform in one or several of these stages leading to char formation depends primarily on the polymer structure. However, this performance can be improved significantly by the use of flame retardants, which are discussed later in the chapter. Although many polymers tend to cross-link at early stages of thermal decomposition, this does not necessarily result in char formation. Char is formed only if the cross-linked polymer contains aromatic fragments and/or conjugated double bonds and is prone to aromatization during thermal decomposition. ${ }^{20}$

Fused aromatic rings in the char tend to assemble into small stacks, which are precursors of graphite. These pregraphitic domains are embedded in the amorphous char. This type of char, called turbostratic char, is usually formed at 600 to $900^{\circ} \mathrm{C}$, temperatures typically found on the surface of burning polymers. Char that contains more pregraphitic domains is more stable to thermal oxidation and therefore less likely to burn away and expose the polymer surface to the heat of the flame. On the other hand, highly graphitized chars are rigid and may have cracks, which do not retard diffusion of combustible materials to the flame. The best-performing char would be amorphous uncracked char with a requisite pregraphitic domain content. 


\subsection{FLAME RETARDANCY}

\subsubsection{General Flame Retardant Mechanisms}

Although flame retardants may differ from one another in terms of chemical structure, certain general mechanisms of action are applicable to various classes of flame retardants. The first line of separation normally distinguishes gas-phase-active and condensed-phase-active flame retardants. Gas-phase-active flame retardants act primarily through scavenging free radicals responsible for the branching of radical chain reactions in the flame. This is the chemical mechanism of action in the gas phase. Other flame retardants generate large amounts of noncombustible gases, which dilute flammable gases, sometimes dissociate endothermically, and decrease the temperature by absorbing heat. This slows combustion and may eventually result in extinguishment of the flame. This is the physical mechanism of action in the gas phase.

Condensed-phase mechanisms of action are more numerous than the gas-phase mechanisms. Charring, discussed briefly above, is the most common condensedphase mode of action. Again, charring could be promoted either by chemical interaction of the flame retardant and the polymer or by physical retention of the polymer in the condensed phase. Charring could also be promoted by catalysis or oxidative dehydrogenation.

Some flame retardants show almost exclusively a physical mode of action. Examples are aluminum hydroxide and magnesium hydroxide. On the other hand, there is no single flame retardant that will operate exclusively through a chemical mode of action. Chemical mechanisms are always accompanied by one or several physical mechanisms, most commonly endothermic dissociation or dilution of fuel. Combinations of several mechanisms can often be synergistic.

\subsubsection{Specific Flame Retardant Mechanisms}

1.3.2.1 Halogen-Containing Flame Retardants Halogen-containing flame retardants represent the most diversified class of retardants. ${ }^{22}$ To be effective, halogen-containing flame retardants need to release halogen in the form of radical or halogen halide at the same temperature range or below the temperature of decomposition of the polymer. ${ }^{23,24}$ Theoretically, four classes of chemical compounds can be used as halogenated flame retardants: those containing fluorine, chlorine, bromine, or iodine. Fluorinated organics are normally more stable than any other polymers and do not release fluorine radicals or hydrogen fluoride. Nevertheless, there are a few examples of the commercial use of fluorinated flame retardants operating differently from all other halogenated flame retardants, and they will be discussed later. By contrast, iodinated organics have very low thermal stability and cannot be processed with most commercial polymers. In addition, fluorine and iodine are more expensive than chlorine or bromine, which also limits development of flame retardants based on these two halogens.

Chlorinated aromatic products are relatively stable and therefore not very efficient, but chlorinated aliphatic and cycloaliphatic flame retardants are well 
known. The chlorine content in some chlorinated paraffins can reach $70 \%$, and some improved grades can be used in polyolefins and in high-impact polystyrene (HIPS). ${ }^{25} \mathrm{~A}$ broad range of brominated flame retardants are commercially available. Brominated flame retardants help maintain a good balance of physical properties, such as good impact and tensile strength and a high heat distortion temperature. These flame retardants are generally suitable for many plastics; however, their principal use is in engineering plastics and epoxy resins. ${ }^{26,27}$ In this case the emphasis is on aromatic products. Although aliphatic brominated flame retardants are often more efficient than aromatics, their use has been limited to certain polymers. ${ }^{28}$ For similar structures there is usually a correlation between degree of bromination and thermal stability. Fully brominated aromatics have low volatility and are used in engineering resins with a relatively high processing temperature. Polymeric and oligomeric brominated aromatic flame retardants are also widely used. In addition to good thermal stability, they show better physical properties. One of the main disadvantages of many brominated aromatic flame retardants is their low resistance to ultraviolet (UV) light; however, there are specially designed commercial flame retardants that show good UV stability.

Figure 1.1 compares the flame retardant efficiency of aliphatic brominated flame retardant and aromatic brominated flame retardant. Because the thermal decomposition of the aliphatic flame retardant starts at temperatures below the thermal decomposition of polypropylene, it shows very good performance in polypropylene. In contrast, because the aromatic brominated fire retardant is significantly more stable, optimum debromination is not achieved at the temperature of decomposition of polypropylene, and this flame retardant shows inferior performance.

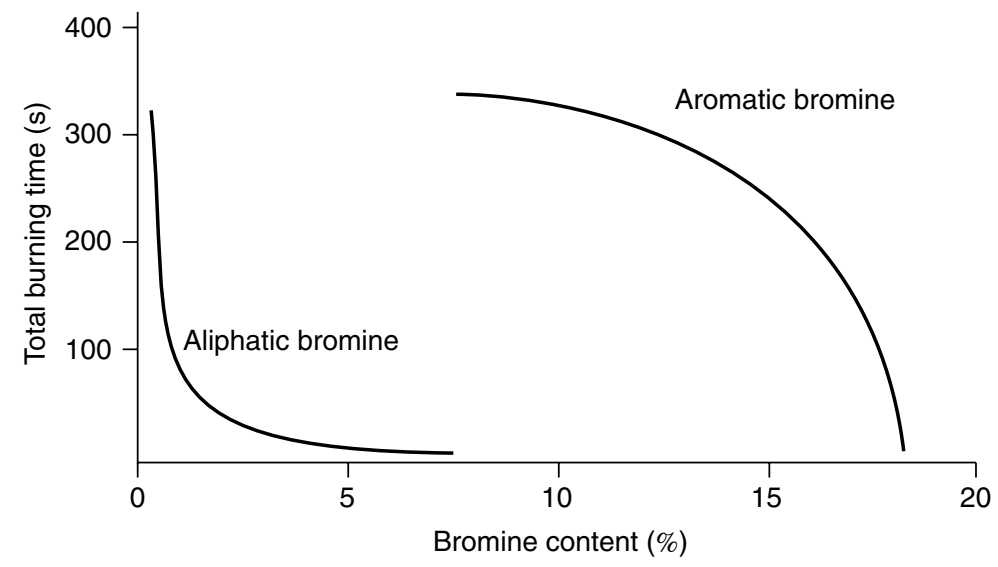

FIGURE 1.1 Dependence of total flaming time of polypropylene measured in a UL-94 test on bromine content for an aliphatic brominated flame retardant and an aromatic brominated flame retardant. (From Ref. 23, copyright (C) 2001, Routledge/Taylor \& Francis Group, with permission.) 
It is generally accepted that the main mechanism of flame retardant action of halogenated flame retardants is in the gas phase, and it is primarily the chemical mode of action. The reaction begins with the abstraction of halogen radical from the flame retardant. This halogen immediately abstracts hydrogen from either the flame retardant additive or the polymer. An example of such a sequence of reactions, with the participation of bromine and an aliphatic polymer, is

$$
\begin{gathered}
\mathrm{R}-\mathrm{Br} \longrightarrow \dot{\mathrm{R}}+\dot{\mathrm{Br}} \\
\dot{\mathrm{Br}}+\mathrm{CH}_{2}-\mathrm{CH}_{2} \longrightarrow \dot{\mathrm{C}} \mathrm{H}-\mathrm{CH}_{2}+\mathrm{HBr} \\
\dot{\mathrm{C}} \mathrm{H}-\mathrm{CH}_{2} \stackrel{-}{\longrightarrow} \mathrm{CH}=\mathrm{CH}
\end{gathered}
$$

In the absence of a synergist, hydrogen halides volatilize and enter the flame. Hydrogen halides will quickly react with hydrogen or hydroxyl radicals and regenerate the halogen. Examples of such reactions with $\mathrm{HBr}$ are shown below in reactions (1.4) and (1.5). Further bromine radicals will react with hydrocarbons in the gas phase and regenerate $\mathrm{HBr}$ as shown in reaction (1.6), with the process repeating until bromine leaves the flame.

Atomic hydrogen and hydroxyl radicals are very important for sustaining combustion. The hydrogen radical is responsible for the chain-branching free-radical reactions in the flame [reaction (1.7)], whereas the hydroxyl radical is responsible for the oxidation of $\mathrm{CO}$ to $\mathrm{CO}_{2}$ [reaction (1.8)], which is a highly exothermic reaction and is responsible for the larger part of the heat generation in the flame.

$$
\begin{gathered}
\mathrm{HBr}+\dot{\mathrm{H}} \longrightarrow \mathrm{H}_{2}+\dot{\mathrm{Br}} \\
\mathrm{HBr}+\dot{\mathrm{O}} \mathrm{H} \longrightarrow \mathrm{H}_{2} \mathrm{O}+\dot{\mathrm{Br}} \\
\dot{\mathrm{Br}}+\mathrm{R}^{\prime} \mathrm{H} \longrightarrow \mathrm{HBr}+\dot{\mathrm{R}} \\
\dot{\mathrm{H}}+\mathrm{O}_{2} \longrightarrow \mathrm{O} \mathrm{H}+\mathrm{O} \\
\mathrm{O} \dot{\mathrm{H}}+\mathrm{CO} \longrightarrow \mathrm{CO}_{2}+\dot{\mathrm{H}}
\end{gathered}
$$

In some other reactions, the more reactive radicals $\left(\mathrm{H}^{*}, \mathrm{OH}^{*}, \mathrm{CH}_{3}{ }^{\circ}\right)$ are replaced by the less active $\mathrm{Br}^{\bullet}$ radicals. ${ }^{29}$ If $\mathrm{Br}^{\bullet}$ meets $\mathrm{H}^{\bullet}$ in the presence of a neutral molecule (third body), $\mathrm{HBr}$ is regenerated. It has been found by spectroscopy that the introduction of halogen-containing inhibitors into the flame clearly reduces the concentration of $\mathrm{H}^{\circ}, \mathrm{OH}^{\circ}$, and $\mathrm{HCO}^{\circ}$ radicals, whereas there is an increase in the content of the diradicals $\mathrm{C}_{2}{ }^{\bullet}$ and soot. As the concentration of inhibitor is increased, the flame temperature decreases. Small additions of halogen inhibitors (on the order of a few $\mathrm{mol} \%$ ) can reduce the rate of flame propagation up to 10fold and have a marked effect on the ignition limits. On the other hand, halogens accelerate the formation of soot in the flame.

It is well established ${ }^{21}$ that $\mathrm{Sb}_{2} \mathrm{O}_{3}$ is synergistic with halogen-containing flame retardants because it facilitates delivery of halogen atoms in the gas phase and prolongs residence of the halogens in the flame zone so that more "hot" radicals 
can be scavenged. Antimony trioxide reacts with $\mathrm{HCl}$ or $\mathrm{HBr}$ in the condensed phase, forming $\mathrm{SbCl}_{3}$ or $\mathrm{SbBr}_{3}$, respectively, both of which are relatively volatile. $\mathrm{SbCl}_{3}$ boils at $223^{\circ} \mathrm{C}$ and $\mathrm{SbBr}_{3}$ boils at $288^{\circ} \mathrm{C}$. Halogenation of $\mathrm{Sb}_{2} \mathrm{O}_{3}$ may or may not proceed through a number of intermediate oxyhalides $\mathrm{Sb}_{n} \mathrm{O}_{m} \mathrm{X}_{p}$, some of which can go into the gas phase as well. ${ }^{30}$ It is also well established that $\mathrm{Sb}_{2} \mathrm{O}_{3}$ catalyses dehalogenation of the flame retardant, ${ }^{31}$ so halogens can be moved into the flame at a lower temperature. In the flame, antimony trihalide (e.g., $\left.\mathrm{SbBr}_{3}\right)$ is reduced step by step to metallic antimony [reaction (1.9)], which could be further oxidized by the oxygen [reaction (1.10)] or hydroxyl radical [reaction (1.11)].

$$
\begin{aligned}
\mathrm{SbBr}_{3}+\dot{\mathrm{H}} \stackrel{-\mathrm{HBr}}{\longrightarrow} \mathrm{SbBr}_{2}+\dot{\mathrm{H}} \stackrel{-\mathrm{HBr}}{\longrightarrow} \mathrm{SbBr}+\dot{\mathrm{H}} \stackrel{-\mathrm{HBr}}{\longrightarrow} \mathrm{Sb} \\
\mathrm{Sb}+\mathrm{O} \longrightarrow \mathrm{SbO} \\
\mathrm{Sb}+\dot{\mathrm{O}} \longrightarrow \mathrm{H} \longrightarrow \mathrm{SbOH}
\end{aligned}
$$

Interference with the antimony-halogen reaction will affect the flame retardancy of the polymer. ${ }^{32}$ For example, metal cations from color pigments or an inert filler such as calcium carbonate or talc may lead to the formation of stable metal halides, rendering the halogen unavailable for reaction with antimony oxide. The result is that neither the halogen nor the antimony is transported into the vapor zone. Silicones have also been shown to interfere with the flame retardant action of halogenated flame retardants.

It is also believed that the large heat capacity of hydrogen halides and their dilution of the flame results in a decrease in the mass concentration of combustible gases and the temperature of the flame. ${ }^{33}$ The physical effect of halogen halides is comparable to that of inert gases, $\mathrm{CO}_{2}$, and water. There is no contradiction between the radical trap theory and the physical theory; apparently, they complement each other. The contribution of each mechanism depends on the temperature of decomposition of the flame retardant additive and the polymer.

As mentioned earlier, the halogen radicals evolved from the flame retardant in the condensed phase abstract the hydrogen from the polymer and produce unsaturation [reactions (1.2) and (1.3)]. The double bonds are known to be precursors of char formation through either cross-linking or aromatization. ${ }^{18}$ If hydrogen is abstracted from the aromatic ring, this ring has a chance to couple with another ring and start forming polyaromatic structures, which are precursors of graphitic domains in the char. This char formation is an important condensed-phase contribution of halogen-based flame retardants, ${ }^{34}$ which is often overlooked.

There is another condensed-phase mode of action that is specific for aliphatic bromine, and it is the opposite of char formation. Bromine radicals generated thermally at low temperature in the polymer melt can cause chain scission at tertiary $\mathrm{C}$ atoms. ${ }^{35,36}$ Examples of polymers where this mechanism is operational are polystyrene (foams) and polypropylene (preferably thin parts, films, or fibers). The decreased molecular weight causes fast dripping of the hot polymer, which cools the flame and eventually extinguishes it: 


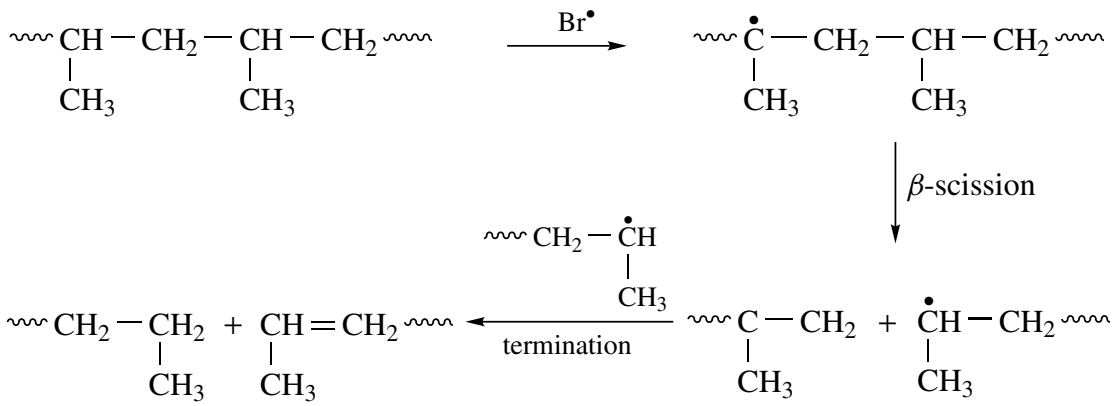

Poly(tetrafluoroethylene) (PTFE) is used at a very low level (0.01 to $0.5 \mathrm{wt} \%)$ in combination with other flame retardants to suppress flaming drips. The flame retardant action of PTFE is not related to any chemical reaction of fluorine or halogen fluoride. During polymer processing at 200 to $300^{\circ} \mathrm{C}$, PTFE particles soften, the shear force of extrusion elongates the particles up to $500 \%$, and microfibrils are formed. Upon combustion the microfibrils shrink back when the polymer melts and a network that prevents dripping is formed. This flame retardant action of PTFE is a physical phenomenon.

Potassium perfluorobutanesulfonate is added to polycarbonate at a low loading of 0.05 to $0.2 \mathrm{wt} \%$ which allows preservation of transparency and clarity of the polymer. Even at such a low concentration, perfluorobutanesulfonate provides a $\mathrm{V}-0$ rating to the polycarbonate. ${ }^{37}$ In this case the sulfonate group is primarily responsible for the flame retardant effect of the product, whereas the perfluorobutane group, due to its strong electron-withdrawing effect, increases the acidity of the sulfonate group. No contribution of hydrogen fluoride is known for potassium perfluorobutanesulfonate.

1.3.2.2 Phosphorus-Based Flame Retardants Phosphorus-based flame retardants are the second most widely used class of flame retardants. Recent efforts in the development of new flame retardants have shifted strongly toward phosphorus and other halogen-free systems. Among phosphorus-based flame retardants, one should distinguish (1) elemental red phosphorus, (2) inorganic phosphates, (3) numerous organic phosphorus-based products, and (4) chlororganophosphates. Although many phosphorus flame retardants exhibit general modes of action, there are specifics for each class mentioned above.

It is generally accepted that phosphorus flame retardants are significantly more effective in oxygen- or nitrogen-containing polymers, which could be either heterochain polymers or polymers with these elements in pendant groups. Effective phosphorus flame retardants are more specific than halogen-based products to certain polymers. This relates to the condensed-phase mechanism of action, where the phosphorus flame retardant reacts with the polymer and is involved in its charring. ${ }^{21}$

The flame retardancy of cellulose has been studied in great detail, which gave good insight for understanding the interaction of phosphorus flame retardants 
with polymers containing hydroxyl groups. ${ }^{38}$ Phosphorus flame retardants, in the form of either acids derived from decomposition of ammonium phosphate salts or of phosphate esters, react (esterify or transesterify) with the hydroxyl groups of the cellulose. ${ }^{39}$ Upon further heating, phosphorylated cellulose undergoes thermal decomposition and a significant amount of char is formed at the expense of combustible volatile products that would be produced by virgin cellulose. Some nitrogen-containing compounds, such as urea, dicyandiamide, and melamine, will accelerate phosphorylation of cellulose through formation of a phosphorus-nitrogen intermediate, and thus synergize the flame retardant action of phosphorus. ${ }^{40}$ Phosphorus-nitrogen synergism is not a general phenomenon but depends on the structure of the phosphorus and nitrogen flame retardants as well as the polymer structure.

Similar to cellulose, phosphate esters can transesterify other polymers. For example, polycarbonates can undergo rearrangement during thermal decomposition, where phenolic $\mathrm{OH}$ groups are formed which then become the target for attack by aromatic phosphate esters ${ }^{41}$ [reaction (1.13)]. Thus, phosphorus is grafted on the polymer chain. Char will be formed upon thermal decomposition of this grafted polymer. Similar phosphorylation chemistry was found for polyphenylene ether (PPE; a component of a PPE/HIPS blend), which also tends to rearrange upon heating and form phenolic $\mathrm{OH}$ groups. ${ }^{42}$
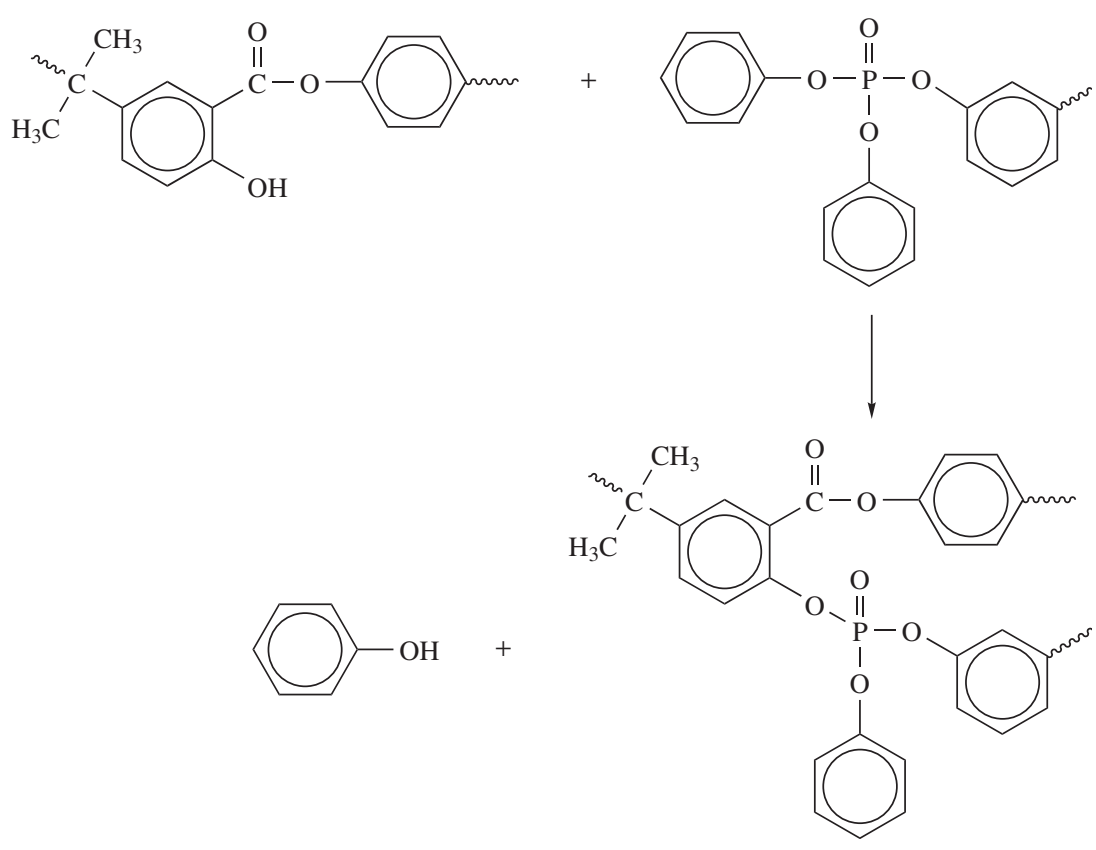

If the polymer cannot be involved in the charring because of the absence of reactive groups, a highly charring coadditive is used in combination with the phosphorus flame retardant. The coadditive is usually a polyol, which can undergo 
phosphorylation similar to that of cellulose; pentaerythritol is a typical example of such a polyol. Melamine can be used in conjunction with this system as well. These combinations of flame retardants are called intumescent systems because they form a viscous swollen char on the surface of the burning polymer. The char impedes the heat flux to the polymer surface and retards diffusion of volatile pyrolysis products to the flame. This mechanism of action is mostly physical because the polymer itself is not necessarily involved in the charring process, but its volatilization is retarded significantly. Intumescent systems for various polymers have been reviewed by Bourbigot et al. ${ }^{43,44}$ The chemistry of formation of the intumescent chars was described thoroughly by Camino et al. ${ }^{45,46}$

Phosphorus flame retardants can remain in the solid phase and promote charring or volatilize into the gas phase, where they act as potent scavengers of $\mathrm{H}^{\bullet}$ or $\mathrm{OH}^{\bullet}$ radicals. Volatile phosphorus compounds are among the most effective inhibitors of combustion. A recent study showed ${ }^{47}$ that phosphorus at the same molar concentration is, on average, five times more effective than bromine and 10 times more effective than chlorine. The mechanism of radical scavenging by phosphorus was suggested by Hastie and Bonnell. ${ }^{48}$ The most abundant phosphorus radicals in the flame are $\mathrm{HPO}_{2}{ }^{\circ}, \mathrm{PO}^{\circ}, \mathrm{PO}_{2}{ }^{\circ}$, and $\mathrm{HPO}^{\circ}$, in decreasing order of significance. Some examples of radical scavenging with participation of $\mathrm{HPO}_{2}{ }^{\bullet}$ and $\mathrm{PO}^{\bullet}$ radicals are shown in reactions (1.14) to (1.18). A third body is required in the reactions involving $\mathrm{PO}^{\bullet}$ radicals.

$$
\begin{aligned}
\mathrm{HPO}_{2}+\dot{\mathrm{H}} & \longrightarrow \mathrm{PO}+\mathrm{H}_{2} \mathrm{O} \\
\mathrm{HPO}_{2}+\dot{\mathrm{H}} & \longrightarrow \mathrm{PO}_{2}+\mathrm{H}_{2} \\
\mathrm{HPO}_{2}+\mathrm{OH} & \longrightarrow \mathrm{PO}_{2}+\mathrm{H}_{2} \mathrm{O} \\
\mathrm{PO}+\dot{\mathrm{H}}+\mathrm{M} & \longrightarrow \mathrm{HPO}+\mathrm{M} \\
\mathrm{PO}+\mathrm{OH}+\mathrm{M} & \longrightarrow \mathrm{HPO}_{2}+\mathrm{M}
\end{aligned}
$$

If conditions are right, phosphorus-based molecules can volatilize and are oxidized, producing active radicals in the flame. On the other hand, phosphorus flame retardants tend to react with the polymer or to oxidize to phosphoric acid in the condensed phase. This favors mostly condensed-phase mechanisms. It is challenging to design a phosphorus-based flame retardant that will volatilize into the flame at relatively low temperatures but will not be lost during polymer processing.

Red phosphorus is the most concentrated source of phosphorus for flame retardancy. In fact, it is very effective in some polymers, such as thermoplastic polyesters or polyamides, where self-extinguishing UL-94 V-0 performance can be achieved at loadings of less than $10 \mathrm{wt} \%$. Despite the apparent chemical simplicity of this additive, its mechanism of action is not completely understood. Most researchers agree ${ }^{49,50}$ that in oxygen- or nitrogen-containing polymers, red phosphorus reacts with the polymer and induces char formation. Although there is a belief that red phosphorus is oxidized and hydrolyzed by water before it 
reacts with the polymer, ${ }^{51,52}$ there is also strong evidence that red phosphorus can react directly with polyesters or polyamides in an inert atmosphere ${ }^{50,53}$ and in the absence of moisture. ${ }^{54}$ There is also some evidence in favor of a freeradical mechanism of interaction between red phosphorus and polyamide- $6 .{ }^{50}$ Red phosphorus shows relatively weak flame retardant effects in hydrocarbon polymers (e.g., polyolefins or polystyrene). It is believed ${ }^{55}$ that in these polymers red phosphorus depolymerizes to white phosphorus, $\mathrm{P}_{4}$, which volatilizes and provides gas-phase action.

Chloroalkyl phosphates, [e.g., tri(1,3-dichloroisopropyl) phosphate or tri(2chloroisopropyl) phosphate or dichloroneopentyl tetrakis(2-chloroethyl) diphosphate] are used primarily in polyurethane foams. It would be logical to assume that chlorine and phosphorus both contribute to the flame retardant efficiency; however, this will depend on the configuration of the test (e.g., upward versus downward or horizontal combustion). The chloroalkyl phosphates are relatively volatile and tend to evaporate when heated with a flame. In downward combustion, the additive, in addition to evaporation, has a chance to react with the polymer, which provides a tarlike residue on the top of the foam, ${ }^{56}$ whereas in upward combustion the additive quickly evaporates, yielding a high concentration of nonflammable flame retardant gases which extinguish the flame. ${ }^{57}$

1.3.2.3 Melamine Flame Retardants Melamine is a unique product with 67 wt\% nitrogen in the molecule and fairly high thermal stability. Melamine also forms thermally stable salts with strong acids. Melamine itself, melamine cyanurate, melamine phosphate, melamine pyrophosphate, and melamine polyphosphate are commercially available for various flame retardant applications. The mechanism of flame retardant action of melamine is different from the mechanism of melamine salts or may be part of the mechanism of action of the salts. In addition, melamine phosphates have specific advantages because of the presence of phosphorus in the molecule.

Melamine is most commonly used in flexible polyurethane foams in combination with chloroalkyl phosphates and in intumescent coatings in combination with ammonium polyphosphate and pentaerythritol. Nevertheless, there is extensive patent literature on the use of melamine in thermoplastics and elastomers, which was reviewed by Weil and Choudhary. ${ }^{58}$ The review gives good insight into the mechanism of flame retardant action of melamine. It is known that melamine does not melt, but sublimes at about $350^{\circ} \mathrm{C}$ (actual volatilization starts at a lower temperature). Upon sublimation, significant energy is absorbed, which decreases the surface temperature of the polymer. This is especially important for polyurethane foams having very low thermal inertia. In a hot flame, melamine may decompose further, with creation of cyanamid, which is also a very endothermic process. ${ }^{58,59}$

Upon heating, to whatever extent it does not sublime away, melamine can undergo progressive condensation with evolution of ammonia and formation of thermally stable condensates, known as melam, melem, and melon. ${ }^{60}$ This reaction competes with melamine volatilization and is more pronounced if the volatilization of melamine is impeded: for example, by trapping in the charred polymer. 
Formation of the residue is considered to be a condensed-phase contribution of melamine, whereas ammonia evolution dilutes the flame with noncombustible gases.

Upon heating, melamine-based salts dissociate, and re-formed melamine volatilizes in a manner similar to pure melamine. However, in the case of melamine salts, a larger portion of melamine undergoes progressive condensation than does pure melamine ${ }^{61}$; therefore, the condensed-phase contribution of the salts is larger. If the anion contains phosphorus, the phosphoric acid released will phosphorylate many polymers and produce a flame retardant effect similar to that of other typical phosphorus-based additives (see above). Melamine condensates and phosphoric acid react further at temperatures above $600^{\circ} \mathrm{C}$, where triazine rings are opened and cross-linked. A (PON) $)_{x}$ type of structure known as phosphorus oxynitride is formed. ${ }^{62}$ Phosphorus oxynitride is very thermally stable and in some polymers can contribute to condensed-phase mechanisms. ${ }^{63}$

Melamine cyanurate is used primarily in unfilled polyamides. ${ }^{64}$ Upon thermal decomposition, melamine is partially volatilized, whereas cyanuric acid catalyzes chain scission of polyamides. This leads to a decrease in melt viscosity and enhanced melt flow and dripping, which removes heat from the polymer and the polymer is extinguished. ${ }^{65,66}$ The vaporizing melamine probably prevents drips from flaming. The fire retardant effect of melamine cyanurate deteriorates significantly in glass-filled polyamides because glass fibers prevent free melt flow. ${ }^{67}$

1.3.2.4 Inorganic Hydroxides Flame Retardants Inorganic hydroxides or mixed hydroxide-inorganic salts that can release water upon heating above $200^{\circ} \mathrm{C}$ can be used as flame retardants in many types of polymers. The two most commonly used products are aluminum hydroxide (ATH) and magnesium hydroxide $(\mathrm{MH})$. In fact, ATH is, by weight, the largest commercially manufactured flame retardant, its main use being in wire and cable insulation and other elastomeric products, synthetic marble and synthetic onyx, latex for carpet back-coatings, phenolics, epoxies, and unsaturated polyesters. ${ }^{68}$ An extensive review of manufacturing, properties, and uses of ATH and other inorganics has been published by Horn. ${ }^{69}$ Mechanisms of fire retardant action of the mineral fillers and their effect on polymer properties have been reviewed by Hornsby and Rothon. ${ }^{70}$

ATH begins to release water at about $220^{\circ} \mathrm{C}$ with an endotherm of $1.17 \mathrm{~kJ} / \mathrm{g}$, whereas $\mathrm{MH}$ starts releasing water at about $330^{\circ} \mathrm{C}$ with an endotherm of $1.356 \mathrm{~kJ} / \mathrm{g}$. Thermogravimetric and differential scanning calorimetry curves obtained on heating of ATH and MH are shown in Figures 1.2 and 1.3, respectively. There is little doubt that the main mechanism of fire retardant action of these hydroxides is heat absorption and dilution of the flame with water vapors. Another mechanism could be the catalytic effect of anhydrous alumina, which will help acid-catalyzed dehydration of some polymers and as a result can enhance charring. ${ }^{38}$ Since both anhydrous alumina and magnesia are white highly refractory powders, they provide heat insulation by reflecting heat when they accumulate on a surface. 


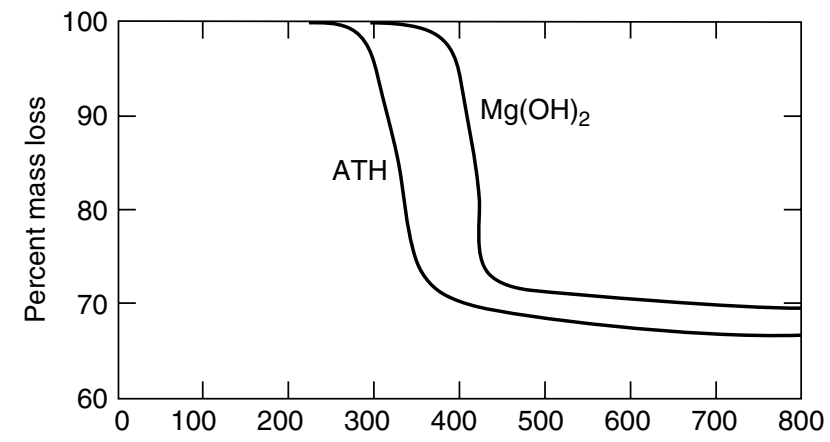

FIGURE 1.2 Thermogravimetry of ATH and $\mathrm{Mg}(\mathrm{OH})_{2}$. (From Ref. 69, copyright (C) 2000, Routledge/Taylor \& Francis Group, with permission.)

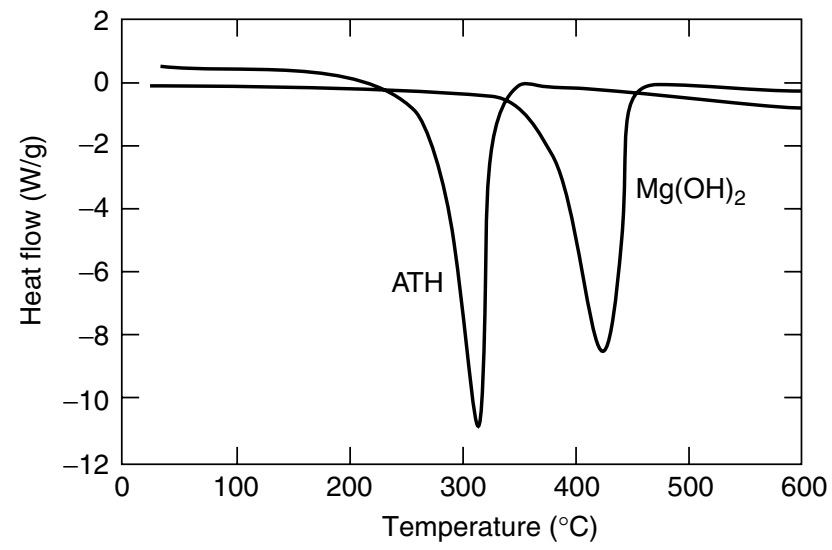

FIGURE 1.3 Differential scanning calorimetry of ATH and $\mathrm{Mg}(\mathrm{OH})_{2}$. (From Ref. 69, copyright (C) 2000, Routledge/Taylor \& Francis Group, with permission.)

ATH and $\mathrm{MH}$ are used primarily in wire and cables in poly(vinyl chloride) (PVC), polyethylene, and various elastomers. There is also some limited application of MH in polyamide- 6 . To pass flame retardancy tests, 35 to $65 \mathrm{wt} \%$ of metal hydroxide is required. Decreasing the loading of metal hydroxides will result in a significant gain in physical properties, especially low-temperature flexibility; therefore, combinations with red phosphorus, silicones ${ }^{69}$ boron compounds, nanoclays ${ }^{71}$ (treated montmorillonites), and charring agents have been explored. ${ }^{72}$ Surface treatment of metal hydroxides also helps to improve physical properties and sometimes improves flame retardancy, due to better dispersion.

1.3.2.5 Borate Flame Retardants Water-soluble borates such as sodium borate (borax) and boric acid have long been used to flame-retard cellulosic materials (e.g., paper boards, wood, and some technical textiles). On the other hand, 
water-insoluble and more thermally stable zinc borates have found use in thermoplastics. The mechanism of fire retardant action of these two types of borates is quite different.

It is believed that soluble borates can esterify the $\mathrm{OH}$ groups of cellulose and promote char formation similar to that of phosphorus. For example, a comparison of the performance of ammonium pentaborate, which decomposes and releases boric acid, and ammonium polyphosphate, which releases polyphosphoric acid, showed some similarity. ${ }^{73}$ Borates and boric acid also release some water, which provides a heat sink. Sodium borate and boric acid or anhydride or their mixtures are low-melting solids. Their viscous glassy melts can cause intumescence by evolved decomposition gases, mostly water, or they can just cover the surface of the pyrolyzing polymer or char, healing cracks and providing a barrier to heat and decomposition products.

Several grades of zinc borates are commercially available, which release different amounts of water. Although in formulas for borates, water is often shown as a water of hydration, in fact, borates are rather complex hydroxide salts. ${ }^{74}$ Upon heating and polymer combustion, zinc borates dehydrate endothermically, and vaporized water absorbs heat and dilutes oxygen and gaseous flammable components. ${ }^{75}$ For example, zinc borate $2 \mathrm{ZnO} \cdot 3 \mathrm{~B}_{2} \mathrm{O}_{3} \cdot 3.5 \mathrm{H}_{2} \mathrm{O}$, known as Firebrake ZB (U.S. Borax), loses about $13.5 \mathrm{wt} \%$ water at 290 to $450^{\circ} \mathrm{C}$ and absorbs $503 \mathrm{~J} / \mathrm{g}$. Thermogravimetric curves of thermal decomposition of various borates are shown in Figure 1.4. Zinc borates are often used in halogen-containing systems and most often in PVC. In PVC, zinc borates significantly increase the amount of char formed during combustion. Zinc borates react with hydrogen chloride released from the thermal decomposition of PVC. Then zinc chloride catalyzes dehydrohalogenation and promotes cross-linking. This leads to an increase

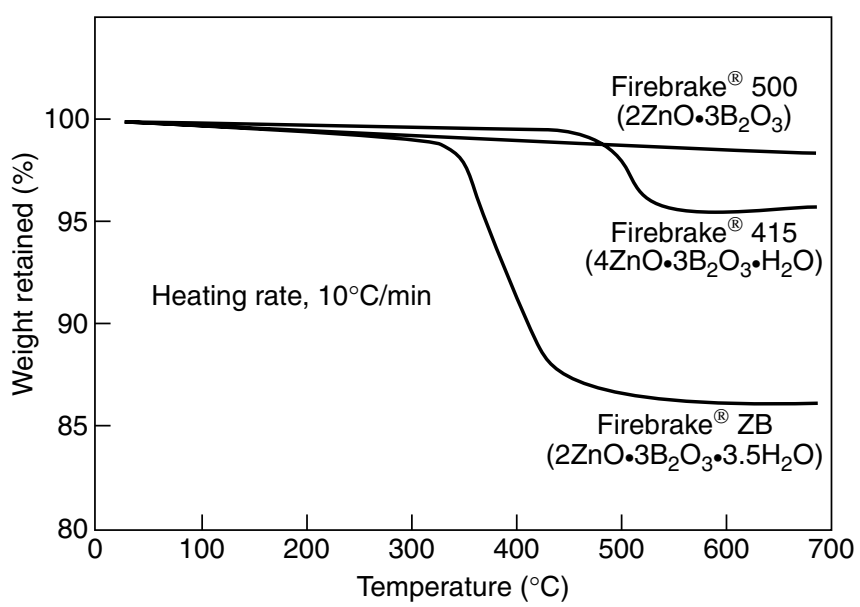

FIGURE 1.4 Thermogravimetry of commercial zinc borates. (From Ref. [76], copyright (C) 2001, American Chemical Society, with permission.) 
in char yield, and, even more important, a significant decrease in smoke formation. At sufficiently high temperatures, zinc borate can melt to produce a glassy layer, but this usually does not happen in small flames. Instead, zinc borate sinters and helps improve the insulating properties of the char and inhibits afterglow combustion.

Zinc borate can also change the oxidative decomposition pathway of halogenfree polymers. It is not completely clear if this is happening because of an inhibition effect of boron oxides toward the oxidation of hydrocarbons ${ }^{75}$ or the oxidation of graphite structures in the char, ${ }^{38}$ or is due purely to the formation of a protective sintered layer. In combination with ATH, zinc borate creates a porous ceramiclike residue, which has much better insulative properties than those of pure anhydrous alumina. It was shown ${ }^{77}$ that zinc borate accelerates dehydration of magnesium hydroxide and creates a ceramiclike structure with dehydrated $\mathrm{MgO}$.

1.3.2.6 Silicon Flame Retardants Under the heading here we include any chemical compound containing Si. For a long time silicons were considered as useful coadditives in flame retardant systems, but recent developments, especially with polycarbonates have again drawn significant attention to silicon. The flame retardancy of silicons has been reviewed by Kashiwagi and Gilman. ${ }^{78}$

Talc is a naturally occurring magnesium silicate which is finding broad application as a filler in polyolefins. Apparently, it provides a moderate flame retardant effect, but because talc is inexpensive, it is used as a partial substitute for more expensive flame retardants. Fumed silica is used as a filler in epoxy resins for the encapsulation of electronic devices at a relatively high loading, up to 80 to $90 \mathrm{wt} \%$. Because of the relatively small amount of combustible resin, this composition can be flame retarded by the addition of a very small amount of a conventional flame retardant. It is not clear if the silica contributes to the flame retardancy by any mechanism other than heat dispersion. Nanodispersed clay, which is one of the main topics of this book, is an aluminosilicate. The mechanism of its flame retardant action is discussed in other chapters of the book.

Octaphenylcyclotetrasiloxane in combination with potassium of sulfonated diphenylsulfone is used commercially in polycarbonate, where clarity of the polymer is important. Recently, some specific branched methylphenylsiloxanes were found particularly effective in polycarbonate (PC) and in PC/acrylonitrilebutadrene-styrene (ABS) blends with a low (ABS) content. ${ }^{79,80}$ It is believed that due to the inclusion of aromatic groups in the siloxane, it becomes significantly more soluble and more easily dispersed in PC than straight polydimethylsiloxane. It was shown that these siloxanes tend to migrate from the inside of the PC resin to the surface during combustion and accumulate quickly on the surface. Such movement resulted from differences in viscosity and solubility between the siloxane and the PC at high temperatures. The branched methylphenylsiloxanes showed a higher thermal stability than that of linear dimethylsiloxanes and a greater tendency to induce charring. In contrast, Nishihara et al. ${ }^{81}$ showed 
that linear polysiloxanes are more advantageous flame retardants in PC than are branched polysiloxanes because of higher mobility in the molten plastic.

1.3.2.7 Synergism The concept of synergism is very often used in the optimization of flame retardant formulations; however, synergism is sometimes misinterpreted. By definition, synergism means enhanced performance of the mixture of two or more components compared to the simple additive performance of the components at the same concentration. Synergism in flame retardancy, and the general concept of synergism, have been reviewed extensively by Weil. ${ }^{40,82}$

The two mostly common examples of synergism, halogens with antimony and phosphorus with nitrogen, were discussed earlier. Apart from $\mathrm{Sb}_{2} \mathrm{O}_{3}$, halogencontaining flame retardants are synergistic with other metal oxides, including $\mathrm{Bi}_{2} \mathrm{O}_{3}, \mathrm{SnO}_{2}, \mathrm{MoO}_{3}, \mathrm{Fe}_{2} \mathrm{O}_{3}$, and $\mathrm{ZnO}$. In some formulations these metal oxides can substitute for $\mathrm{Sb}_{2} \mathrm{O}_{3}$ partially or completely. Zinc borates or zinc sulfide can be used in the same role of partial substitution of $\mathrm{Sb}_{2} \mathrm{O}_{3}$. In many instances these metal oxides also provide additional advantages of smoke suppression.

A very sharp synergistic effect between ammonium polyphosphate (APP) and some inorganic minerals, salts, and oxides in a narrow concentration range was discovered independently by Levchik et al. ${ }^{83-86}$ and by Lewin et al. ${ }^{87-89}$ Later, similar effects were noted in systems containing ammonium polyphosphate and zeolite. ${ }^{90,91}$ Although different speculative mechanisms of catalysis of charring (e.g., by zeolites), or thermal oxidative promotion of charring by manganese dioxide were proposed, these mechanisms probably play a minor role. The principal mechanism appears to be interaction of polyphosphoric acid formed during thermal decomposition of APP and metal-containing compounds. Since only divalent and higher-valency metals show this effect, it is reasonable to assume that metal cations help to cross-link polyphosphoric acid and increase its viscosity. This, in turn, helps to create a more thermally insulative char structure. If the mineral compound is added in large quantities, solid crystalline phosphates are formed, and this results in cracking of the char and the loss of insulating properties. This also explains why this synergistic effect is observed in a very narrow concentration range.

Because of increased attention to halogen-free systems in recent years, there has also been a significant effort to enhance the fire retardant performance of aluminum hydroxide (ATH) and magnesium hydroxide $(\mathrm{MH})$, because these additives are used at very high loading levels. It is interesting that just a simple combination of ATH and MH can be synergistic. ${ }^{40}$ This probably relates to the extension of the temperature interval for the elimination of water. Combinations of $\mathrm{MH}$ and zinc borate were found to be synergistic in poly(ethylene-co-vinyl acetate), (EVA) according to a cone calorimeter study. ${ }^{77}$ It was found that zinc borate catalyzes dehydration of $\mathrm{MH}$. In addition, zinc borate helps to sinter particles of $\mathrm{MgO}$ together, which, in turn, leads to better retention of combustible polymer in the condensed phase and eventual charring. Further addition to $\mathrm{MH}$ and zinc borate to nanoclay and low-melting glass allowed achievement of a $\mathrm{V}-0$ rating in the UL-94 test. $^{72}$ 


\subsubsection{Criteria for Selection of Flame Retardants}

Criteria for the selection of flame retardants are usually based on:

- The efficiency of a particular type of flame retardant in a particular polymer system

- The processing conditions of the polymer

- Compatibility and the ability to preserve valuable physical properties

- The cost-performance trade-off

As mentioned above, halogenated flame retardants are more universal than phosphorus-based flame retardants because the halogenated retardants are effective primarily in the flame zone, which is chemically similar for many polymers. However, other criteria listed above require halogenated flame retardants to be tailored to specific polymers. For example, aliphatic halogenated flame retardants are used primarily in thermoset resins or in expandable polystyrene, because of their limited thermal stability. Flame retardants that are soluble in polystyrene are not good for HIPS, because solubility results in plasticization and a dramatic decrease in the heat distortion temperature. On the other hand, partially soluble additives (e.g., decabromodiphenyl oxide) are very suitable for HIPS because they help keep an acceptable heat distortion temperature and good impact properties. Although ABS is chemically similar to HIPS, additives that are soluble in polystyrene (e.g., tetrabromobisphenol A or brominated epoxy oligomers) are preferable. Because ABS has a higher rubber content than HIPS, the use of insoluble additives is detrimental for polymer toughness.

Phosphorus-based flame retardants are usually more suitable for engineering plastics that undergo charring than for commodity polymers. In some plastics, such as PC-ABS or poly(phenylene oxide)-HIPS blends, phosphorus-based flame retardants are more effective then halogenated flame retardants. Antimony trioxide, which is a part of halogen-containing formulations, is a Lewis acid and may destabilize some condensation polymers. Furthermore, the impact properties of engineering polymers may suffer due to the presence of powdery antimony trioxide.

Inorganic hydroxides are used at very high loading levels. Only certain polymers, e.g., polyolefins, can tolerate such high loading without a significant loss of physical properties. Furthermore, relatively low thermal stability, especially of ATH, significantly limits the use of inorganic hydroxides. Other polymeric systems in which ATH is used are PVC, unsaturated polyesters, and latex backcoatings of polyamide or polyester carpets.

\subsubsection{Highly Dispersed Flame Retardants}

Flame retardants of very small particle size were always of great interest. As mentioned earlier, fumed silica, which apparently has some flame retardant action, is widely used in epoxy formulations for encapsulation of electronic elements. 
Another example is use of $0.1-$ to $2.0-\mu \mathrm{m}$ size $\mathrm{Sb}_{2} \mathrm{O}_{3}$, which helps not only with good flame retardancy but also with good pigmentation of PVC. ${ }^{92}$ Colloidal-size $(0.03 \mu \mathrm{m})$ antimony pentoxide, which has a much lower refractive index than $\mathrm{Sb}_{2} \mathrm{O}_{3}$, can be used in transparent PVC applications. ${ }^{93}$ In transparent polycarbonate applications, very small amounts (in the range of $0.02 \mathrm{wt} \%$ ) of halogenated sulfonate salts, also of submicron particle size, ${ }^{94}$ are used. Very fine particle metal oxides can also be used in the flame retardancy of polycarbonate ${ }^{95}$, however, apparently this use did not find commercial application. A significant amount of melamine of micrometer and submicrometer particle size which is dispersable in the polyol is used in the flame retardancy of polyurethane foams. ${ }^{96}$

It was always thought that flame retardants of submicrometer particle size would have an essential advantage over flame retardants of regular particle size (micrometer and above) in terms of efficiency. Practice proved that this is true only to a certain extent and depends very much on the type of flame retardant and the flame retardant test used. For example, some phosphate esters and brominated flame retardants are soluble in a polymer matrix. Obviously, it is impossible to achieve better than this distribution for any solid flame retardant, and it is known that these soluble flame retardants do not show extraordinary efficiency compared to their solid counterparts dispersed in the polymers. There is a large class of flame retardants that will melt before they start interacting with the polymer and provide a flame retardant effect. It is clear that little can be achieved by using very fine particles of such flame retardants. A similar comment applies to flame retardants that decompose and totally disintegrate before interacting with the polymer.

A number of publications have shown the advantages of using highly dispersed $\mathrm{ATH}^{97,98}$ or $\mathrm{MH}^{99}$ The average size of the particles of these specially prepared hydroxides is in the range 100 to $300 \mathrm{~nm}$ and the authors qualify them as nanofillers. Usually, no or very little advantage is seen with these nanoscale hydroxides in terms of the LOI and UL-94 tests, but some advantages are observed in cone calorimetry. In another study, an attempt was made to flameretard poly(methyl methacrylate) with fumed silica. ${ }^{97}$ Even at relatively high loadings of the silica, only marginal improvement in LOI values was observed. A decrease in the heat release rate measured in cone calorimetry is the commonly seen advantage of nanoscale particles, including nanoclays (discussed in detail in other chapters). Although many mechanistic studies on flame retardancy of nanocomposites are in progress, there is an often accepted point of view that because of their small size, nanoparticles can sinter and create a ceramic-carbon coke on the surface of a polymer which insulates it from heat. Because the flames are small in the LOI and UL-94 tests, they do not provide enough heat for sintering, and that effect of nanoparticles is not seen.

There is another physical mode of action of micro- or nanoscale particles, often overlooked, which is related to the change in rheology of the polymer melt. Even a few percent loading can decrease melt flow significantly. This change in melt viscosity does not itself make it possible to pass the flame retardant test, but in combination with other flame retardants it can be an important tool for improving performance. For example, formulations passing the UL-94 test with a V-2 rating 
can be upgraded to $\mathrm{V}-1$ or even $\mathrm{V}-0$ with the addition of $<1 \mathrm{wt} \%$ of a nanofiller. The effect in the LOI test could be negative or positive. If melt flow contributes to high LOI numbers and will be suppressed by the presence of a nanofiller, the LOI value may actually decrease. This is just an example of a controversy that often appears in the literature and sometimes leads to erroneous conclusions.

\subsection{CONCLUSIONS AND FUTURE OUTLOOK}

Without a doubt, many chemical substances of high toxicity are released in largescale fires. ${ }^{100}$ But if the occupants have a chance to escape the fire, these toxicants become irrelevant. If the occupants do not escape, they will be victims regardless of the relative toxicity of the flame retardants. The ability of flame retardants to delay fire spread must be recognized as being more important than the relative toxicities of these chemicals when they are decomposed in a fire situation. A study ${ }^{101}$ using the life-cycle assessment model, incorporating the emissions from fires, has been applied to furniture. It was found that the largest environmental impact comes from non-flame retardant furniture because of the extensive evolution of polyaromatic hydrocarbons (PAHs), which are strong carcinogens. On the other hand, the environmental impact due to the evolution of chlorinated or brominated dioxins is much less significant. Numerous studies confirm that there is no significant difference in the toxicity of combustion gases from flame-retarded and non-flame-retarded materials. ${ }^{19}$ The difference is in the concentration. Since flame retardant materials burn more slowly and often self-extinguish, they generate less toxic gases. Therefore, a true environmental benefit can be achieved only if there are fewer and smaller fires.

The most publicized issue in flame retardants nowadays is the potential replacement of some brominated flame retardants with nonhalogenated flame retardants due to environmental concerns with some halogenated materials. ${ }^{102}$ There is also a belief, especially in Europe and the Far East, that halogen-containing flame retardant can evolve small amount of dioxins or dibenzofurans when heated and that plastics containing these flame retardants are therefore not suitable for recycling or incineration. Because of lack of alternative flame retardants, the use of halogen-containing flame retardants has been restricted in Europe and Japan. This has led some manufacturers to eliminate voluntarily the use of flame retardants: mostly because of "environmental" reasons and but because of cost saving as well. Thus, the drive to reduce cost and be more competitive while having a "green" image led to badly compromised fire safety. Considerable loss of life occurred from small ignition sources causing severe burning of non-flameretarded TV sets. The European regulation regarding electrical and electronic device waste disposal, which requires separate treatment of halogen-containing parts, is another driver for the use of nonhalogen flame retardants or the complete avoidance of flame retardants.

It is clear that there is a great demand for environmentally friendly (usually construed to mean halogen-free) and easily recyclable flame 
retardant thermoplastics. However, this requirement is in conflict with another environmental requirement, biodegradation. Normally, thermally and hydrolytically stable products, which are required for multiple recycling, tend to be persistent in nature. Therefore, for the future design of flame retardants it is important to make a distinction between one-time short-period-use products, which are biodegradable, and long-term stable products, which are subject to recycling. However, even very thermally and hydrolytically stable flame retardants should eventually be destroyed, either thermally or chemically, under controlled conditions. Newly developed flame retardants should comply with these requirements.

\section{REFERENCES}

1. Hirschler, M. Fire performance of organic polymers, thermal decomposition, and chemical composition, in: G.L. Nelson and C.A. Wilkie, Eds. Fire and Polymers: Materials and Solutions for Hazard Prevention. ACS Symposium Series, Vol. 797. American Chemical Society, Washington, DC, 2001, pp. 293-306.

2. Purser, D.A. Toxic product yields and hazard assessment for fully enclosed design fires. Polym. Int. 2000, 49, 1232-1255.

3. Irvine, D.J.; McCluskey, J.A.; Robinson, I.M. Fire hazards and some common polymers. Polym. Degrad. Stab. 2000, 67, 383-396.

4. Troitzsch, J.H. Fire gas toxicity and pollutants in fires: the role of flame retardants, in: Flame Retardants 2000. Interscience Communications, London, 2000, pp. 177-184.

5. Hirschler, M.M. Fire retardance, smoke toxicity and fire hazard, in: Flame Retardants '94. Interscience Communications, London, 1994, pp. 225-238.

6. Hirschler, M.M. Fire hazard and smoke toxicity: post-flashover fire issues or Incapacitation via Irritancy, in: Flame Retardants 2000. Interscience Communications, London, 2000, pp. 193-204.

7. Stevenson, G.C. Countervailing risks and benefits in the use of flame retardants, in: Flame Retardants 2000. Interscience Communications, London, 2000, pp. 131-145.

8. Manor-Orit, G.-P. Flame retardants and the environment. Spec. Chem., 2005, 25(7), 36(4).

9. Green, J. 25 years of flame retarding plastics, in: Proceedings of the 7th Conference on Recent Advances in Flame Retardancy of Polymeric Materials, Stamford, CT, 1996.

10. Nelson, G.L. The changing nature of fire retardancy in polymers, in: A.F. Grand and C.A. Wilkie, Eds., Fire Retardancy of Polymeric Materials. Marcel Dekker, New York, 2000, pp. 1-26.

11. Babrauskas, V.; Harris, R.H., Jr.; Gann, R.G.; Levin, B.C.; Lee, B.T.; Peacock, R.D.; Paabo, M.; Twilley, W.; Yoklavich, M.F.; Clark, H.M. Fire Hazard Comparison of Fire-Retarded and Non-Fire-Retarded Products. NBS Special Publication 749. National Bureau of Standards, Gaithersburg, MD, 1988.

12. Hirschler, M.M. Residential upholstered furniture in the United States and fire hazard, in: Proceedings of the 15th Conference on Recent Advances in Flame Retardancy of Polymeric Materials, Stamford, CT, 2004. 
13. Troitzsch, J., Ed. Plastics Flammability Handbook: Principles, Regulations, Testing, and Approval, 3rd ed. Carl Hanser Verlag, Munich, Germany, 2004.

14. Babrauskas, V. Burning rates, in: SFPE Handbook of Fire Protection Engineering, 2nd ed. National Fire Protection Association, Quincy, MA, 1996, pp. 3-53.

15. Babrauskas, V. Ignition Handbook. Fire Science Publishers, Issaquah, WA, 2003.

16. Williams, M.K.; Nelson, G.L.; Brenner, J.R.; Weiser, E.S.; Clair, T.L. Cell surface area and foam flammability, in: Proceedings of the 12th Conference on Recent Advances in Flame Retardancy of Polymeric Materials, Stamford, CT, 2001.

17. Van Klevelen, D.W. Some basic aspects of flame resistance of polymeric materials. Polymer, 1975, 16, 615-620.

18. Levchik, S.; Wilkie, C.A. Char formation, in: A.F. Grand and C.A. Wilkie, Eds., Fire Retardancy of Polymeric Materials. Marcel Dekker, New York, 2000, pp. 171215.

19. Hirschler, M.M. Chemical aspects of thermal decomposition, in: A.F. Grand and C.A. Wilkie, Eds., Fire Retardancy of Polymeric Materials. Marcel Dekker, New York, 2000, pp. 27-79.

20. Wilkie, C.A.; Levchik S.V.; Levchik G.F. Is there a correlation between crosslinking and thermal stability? in: S. Al-Malaika, A. Golovoy, and C.A. Wilkie, Eds., Specialty Polymer Additives: Principles and Application. Blackwell Science, Oxford, England, 2001, pp. 359-374.

21. Aseeva, R.M.; Zaikov, G.E. Combustion of Polymer Materials. Carl Hanser Verlag, Munich, Germany, 1986, p. 149.

22. Georlette, P.; Simons, J.; Costa, L. Halogen-containing fire-retardant compounds, in: A.F. Grand and C.A. Wilkie, Eds., Fire Retardancy of Polymeric Materials. Marcel Dekker, New York, 2000, pp. 245-284.

23. Georlette, P. Applications of halogen flame retardants, in: A.R. Horrocks and D. Price, Eds., Fire Retardant Materials. Woodhead Publishing, Cambridge, England, 2001, pp. 264-292.

24. Murphy, J. Flame retardants: trends and new developments. Plast. Add. Compound. 2001, Apr., pp. 16-20.

25. Stevenson, D.; Lee, V.; Stein, D.; Shah, T. Flame retardant formulations for HIPS and polyolefins using chlorinated paraffins, in: Proceedings of the Spring FRCA Conference, San Antonio, TX, 2002, pp. 79-90.

26. Bie, F. The crucial question in fire protection. Eng. Plast. 2002, 92(2), 27-29.

27. Litzenburger, A. Criteria for, and examples of optimal choice of flame retardants. Polym. Polym. Compos. 2000, 8, 581-592.

28. Finberg, I.; Bar Yaakov, Y.; Georlette, P.; Squires, G.; Geran, T. Fire retardant efficiency and properties of aliphatic bromine compounds in styrenic copolymers, in: Proceedings of the 12th Conference on Recent Advances in Flame Retardancy of Polymeric Materials, Stamford, CT, 2001.

29. Boryniec, S.; Przygocki, W. Polymer combustion processes, 3: Flame retardants for polymeric materials. Prog. Rubber Plast. Technol. 2001, 17, 127-148.

30. Pitts, J.J.; Scott, P.H.; Powell, D.G. Thermal decomposition of antimony oxychloride and mode in flame retardancy. J. Cell. Plast. 1970, 6, 35-37. 
31. Starnes, W.H., Jr. Kang, Y.M.; Payne, L.B. Reductive dechlorination of a cycloaliphatic fire retardant by antimony trioxide and nylon 6,6: implications for the synergism of antimony and chlorine, in: G.L. Nelson and C.A. Wilkie, Eds., Fire and Polymers: Materials and Solutions for Hazard Prevention. ACS Symposium Series, Vol. 797. American Clinical Society, Washington, DC, 2001, pp. 228-239.

32. Green, J. Mechanisms for flame retardancy and smoke suppression: a review. J. Fire Sci. 1996, 14, 426-442.

33. Lewin, M. Physical and chemical mechanisms of flame retarding of polymers, in: M. Le Bras, G. Camino, S. Bourbigot, and R. Delobel, Eds., Fire Retardancy of Polymers: The Use of Intumescence. Royal Society of Chemistry, London, 1998, pp. 3-32.

34. Pearce, E.M.; Shalaby, S.W.; Barker, R.H. Retarding combustion of polyamides, in: M. Lewin, S.M. Atlas, and E.M. Pearce, Eds., Flame-Retardant Polymeric Materials, Vol. 1. Plenum Press, New York, 1975, pp. 239-290.

35. Kaspersma, J.H. FR mechanism aspects of bromine and phosphorus compounds, in: Proceedings of the 13th Conference on Recent Advances in Flame Retardancy of Polymeric Materials, Stamford, CT, 2002.

36. Prins, A.-M.; Doumer, C.; Kaspersma, J. Glow wire and V-2 performance of brominated flame retardants in polypropylene, in: Flame Retardants 2000. Interscience Communications, London, 2000, pp. 77-85.

37. Tanaka, A.; Kanai, T. Thermal decomposition behavior and flame retardancy of polycarbonate containing organic metal salts: effect of salt composition. J. Appl. Polym. Sci. 2004, 94, 2131-2139.

38. Lewin, M.; Weil, E.D. Mechanisms and modes of action in flame retardancy of polymers, in: A.R. Horrocks and D. Price, Eds., Fire Retardant Materials. Woodhead Publishing, Cambridge, England, 2001, pp. 31-68.

39. Kandola, B.K.; Horrocks, A.R.; Price, D.; Coleman, G.V. Flame retardant treatments of cellulose and their influence on cellulose pyrolysis. J. Macromol. Sci. Rev. Macromol. Chem. Phys. 1996, C36, 721-794.

40. Weil, E.D. Synergists, adjuvants and antagonists in flame retardant systems, in: A.F. Grand and C.A. Wilkie, Eds., Fire Retardancy of Polymeric Materials. Marcel Dekker, New York, 1999, pp. 115-145.

41. Murashko, E.A.; Levchik, G.F.; Levchik, S.V.; Bright, D.A.; Dashevsky, S. Fire retardant action of resorcinol bis(diphenyl phosphate) in PC-ABS blend, II: Reactions in the condensed phase. J. Appl. Polym. Sci. 1999, 71, 1863-1872.

42. Murashko, E.A.; Levchik, G.F.; Levchik, S.V.; Bright, D.A.; Dashevsky, S. Fire retardant action of resorcinol bis(diphenyl phosphate) in a PPO/HIPS blend. J. Fire Sci. 1998, 16, 233-249.

43. Bourbigot, S.; Le Bras, M.; Duquesne, S.; Rochery, M. Recent advances for intumescent polymers. Macromol. Mater. Eng. 2004, 289, 499-511.

44. Bourbigot, S.; Le Bras, M. Flame retardants, in: J. Troitzsch, Ed., Plastics Flammability Handbook. Carl Hanser Verlag, Munich, Germany, 2004, pp. 133-157.

45. Camino, G.; Delobel, R. Intumescence, in: A.F. Grand and C.A. Wilkie, Eds., Fire Retardancy of Polymeric Materials. Marcel Dekker, New York, 2000, pp. 217-243.

46. Camino, G.; Lomakin, S. Intumescent materials, in: A.R. Horrocks and D. Price, Eds., Fire Retardant Materials. Woodhead Publishing, Cambridge, England, 2001, pp. 318-336. 
47. Babushok, V.; Tsang, W. Inhibitor rankings for alkane combustion. Combust. Flame, 2000, 124, 488-506.

48. Hastie, J.W.; Bonnell, D.W. Molecular Basis of Inhibited Combustion Systems. NBS Research Report NBSIR 80-2169. National Bureau of Standards, Gaithersburg, MD, 1980.

49. Alfonso, G.C.; Costa, G.; Pasolini, M.; Russo, S.; Ballistreri, A.; Montaudo, G.; Puglisi, C. Flame-resistant polycaproamide by anionic polymerization of $\varepsilon$-caprolactam in the presence of suitable flame-retardant agents. J. Appl. Polym. Sci. 1986, 31, $1373-1382$.

50. Levchik, G.F.; Levchik, S.V.; Camino, G.; Weil, E.D. Fire retardant action of red phosphorus in nylon 6, in: M. Le Bras, G. Camino, S. Bourbigot, and R. Delobel, Eds., Fire Retardancy of Polymers: The Use of Intumescence. Royal Society of Chemistry London, 1998, pp. 304-315.

51. Ballistreri, A.; Foti, S.; Montaudo G.; Scamporino, E.; Arnesano, A.; Calgari, S. Thermal decomposition of flame retardant acrylonitrile polymers, 2: Effect of red phosphorus. Makromol. Chem. 1981, 182, 1301-1306.

52. Ballistreri, A.; Montaudo, G.; Puglisi, C.; Scamporino, E.; Vitalini, D.; Calgari, S. Mechanism of flame retardant action of red phosphorus in polyacrylonitrile. J. Polym. Sci. Polym. Chem. 1983, 21, 679-689.

53. Kuper, G.; Hormes, J.; Sommer, K. In situ X-ray absorption spectroscopy at the K-edge of red phosphorus in polyamide 6,6 during a thermo-oxidative degradation. Makromol. Chem. Phys. 1994, 195, 1741-1753.

54. Levchik, G.F.; Vorobyova, S.A.; Gorbarenko, V.V.; Levchik, S.V.; Weil, E.D. Some mechanistic aspects of the fire retardant action of red phosphorus in aliphatic nylons. J. Fire Sci. 2000, 18, 172-182.

55. Braun, U.; Schartel, B. Fire retardancy mechanisms of red phosphorus in thermoplastics, in: Proceedings of the Additives 2003 Conference, San Francisco, CA, 2003.

56. Ravey, M.; Keidar, I.; Weil, E.D.; Pearce, E.M. Flexible polyurethane foam, II: Fire retardation by tris(1,3-dichloro-2-propyl) phosphate, A: Examination of the vapor phase (the flame). J. Appl. Polym. Sci. 1998, 68, 217-229.

57. Ravey, M.; Weil, E.D.; Keidar, I.; Pearce, E.M. Flexible polyurethane foam, II: Fire retardation by tris(1,3-dichloro-2-propyl) phosphate, B: Examination of the condensed phase (the pyrolysis zone). J. Appl. Polym. Sci. 1998, 68, 231-254.

58. Weil, E.D.; Choudhary, V. Flame-retarding plastics and elastomers with melamine. J. Fire Sci. 1995, 13, 104-126.

59. Weil, E.D.; Zhu, W. Some practical and theoretical aspects of melamine as a flame retardant, in: G.L. Gordon, Ed., Fire and Polymers II: Materials and Tests for Hazard Prevention. ACS Symposium Series, Vol. 599. American Chemical Society, Washington, DC, 1994, pp. 199-220.

60. Bann, B.; Miller, S.A. Melamine and derivatives of melamine. Chem. Rev. 1958, $58,131-172$.

61. Costa, L.; Camino, G.; Luda di Cortemiglia, M.P. Mechanism of thermal degradation of fire-retardant melamine salts, in: G.L. Nelson, Ed., Fire and Polymers: Hazard Identification and Prevention. ACS Symposium Series, Vol. 425. American Chemical Society, Washington, DC, 1990, pp. 211-238.

62. Weil, E.D. Melamine phosphate flame retardants. Plast. Compound. 1994, MayJune, pp. 31-39. 
63. Levchik, S.V.; Levchik, G.F.; Balabanovich, A.I.; Weil, E.D.; Klatt, M. Phosphorus oxynitride, a thermally stable fire retardant additive for polyamide 6 and polybutylene terephthalate. Angew. Makromol. Chem. 1999, 264, 48-55.

64. Kaprinidis, N.; Zingg, J. Overview of flame retardant compositions UV stable flame retardant systems and antimony free flame retardant products for polyolefins: halogen free melamine based flame retardants for polyamides, in: Proceedings of the Spring FRCA Conference, New Orleans, LA, 2003, pp. 168-175.

65. Levchik, S.V.; Balabanovich, A.I.; Levchik, G.F.; Costa, L. Effect of melamine and its salts on combustion and thermal decomposition of polyamide 6. Fire Mater. 1997, 21, 75-83.

66. Endtner, J.M. Development of new halogen-free flame retardant engineering plastics by application of automated optical investigation methods, in: Proceedings of the 16th Conference on Recent Advances in Flame Retardancy of Polymeric Materials, Stamford, CT, 2005.

67. Casu, A.; Camino, G.; De Giorgi, M.; Flath, D.; Morone, V.; Zenoni, R. Fireretardant mechanistic aspects of melamine cyanurate in polyamide copolymer. Polym. Degrad. Stab. 1997, 58, 297-302.

68. Fink, U. The market situation, in: J. Troitzsch, Ed., Plastics Flammability Handbook. Carl Hanser Verlag, Munich, Germany, 2004, pp. 8-32.

69. Horn, W.E., Jr. Inorganic hydroxides and hydroxycarbonates: their function and use as flame retardant additives, in: A.F. Grand and C.A. Wilkie, Eds., Fire Retardancy of Polymeric Materials. Marcel Dekker, New York, 2000, pp. 285-352.

70. Hornsby, P.R.; Rothon, R.N. Fire retardant fillers for polymers, in: M. Le Bras, C.A. Wilkie, S. Bourbigot, S. Duquesne, and C. Jama, Eds., Fire Retardancy of Polymers: New Applications of Mineral Fillers. Royal Society of Chemistry, London, 2005, pp. 19-41.

71. Beyer, G. Nanocomposites: a new concept for flame retardant polymers: Polym. News 2001, 26, 370-378.

72. Weil, E.D.; Lewin, M.; Rao, D. A search for an interactive flame retardant system for ethylene-vinyl acetate, in: Proceedings of the 15th Conference on Recent Advances in Flame Retardancy of Polymeric Materials, Stamford, CT, 2004.

73. Levchik, G.F.; Levchik, S.V.; Selevich, A.F.; Lesnikovich, A.I. The effect of ammonium pentaborate on combustion and thermal decomposition of polyamide 6. Vesti Akad. Nauk. Belarusi Ser. Khim. Nauk, 1995, 3, 34-39.

74. Shen, K.K.; Griffin, T.S. Zinc borate as a flame retardant, smoke suppressant, and afterglow suppressant in polymers, in: G.L. Nelson, Eds., Fire and Materials: Hazards Identification and Prevention. ACS Symposium Series, Vol. 425. American Chemical Society, Washington, DC, 1990, pp. 157-177.

75. Yang, Y.; Shi, X.; Zhao, R. Flame retardancy behavior of zinc borate. J. Fire Sci. 1999, 17, 355-361.

76. Shen, K.K. Zinc borates: 30 years of successful development as multifunctional fire retardants, in: G.L. Nelson and C.A. Wilkie, Eds., Fire and Polymers: Materials and Solutions for Hazard Prevention. ACS Symposium Series, Vol. 797. American Chemical Society, Washington, DC, 2001 pp. 228-239.

77. Bourbigot, S.; Carpentier, F.; Le Bras, M.; Fernandez, C. Mode of action of zinc borates in flame-retardant EVA-metal hydroxide systems, in: S. Al-Malaika, 
A. Golovoy, and C.A. Wilkie, Eds., Specialty Polymer Additives: Principles and Applications. Blackwell Science, Oxford, England, 2001, pp. 271-292.

78. Kashiwagi, T.; Gilman, J.W. Silicon-based flame retardants, in: S. Al-Malaika, A. Golovoy, and C.A. Wilkie, Eds., Specialty Polymer Additives: Principles and Applications. Blackwell Science, Oxford, England, 2001, pp. 353-389.

79. Iji, M.; Serizawa, S. Silicone derivatives as new flame retardants for aromatic thermoplastics used in electronic devices. Polym. Adv. Technol. 1998, 9, 543-600.

80. Iji, M.; Serizawa, S. New silicone flame retardant for polycarbonate and its derivatives, in: S. Al-Malaika, A. Golovoy, and C.A. Wilkie, Eds., Specialty Polymer Additives. Principles and Applications. Blackwell Science, Oxford, England, 2001, pp. 293-302.

81. Nishihara, H.; Suda, Y.; Sakuma, T. Halogen- and phosphorus-free flame retardant PC plastic with excellent moldability and recyclability. J. Fire Sci. 2003, 21, 451-464.

82. Weil, E. Additivity, synergism and antagonism in flame retardancy, in: W.C. Kuryla and A.J. Papa, Eds., Flame Retardancy of Polymeric Materials, Vol. 3. Marcel Dekker, New York, 1975, pp. 185-243.

83. Levchik, S.V; Levchik, G.F.; Selevich, A.F.; Camino, G.; Costa, L. Effect of talc on nylon 6 fire retarded with ammonium polyphosphate, in: Proceedings of the 2nd Beijing International Symposium/Exhibition on Flame Retardants, Beijing, China, 1993, pp. 197-202.

84. Levchik, S.V.; Levchik, G.F.; Camino, G.; Costa, L. Mechanism of action of phosphorus-based flame retardants in nylon 6, II: Ammonium polyphosphate/talc. J. Fire Sci. 1995, 13, 43-58.

85. Levchik, S.V.; Levchik, G.F.; Camino, G.; Costa, L.; Lesnikovich, A.I. Mechanism of action of phosphorus-based flame retardants in nylon 6, III: Ammonium polyphosphate/manganese dioxide. Fire Mater. 1996, 20, 183-190.

86. Levchik, G.F.; Levchik, S.V.; Lesnikovich, A.I. Mechanisms of action in flame retardant reinforced nylon 6. Polym. Degrad. Stab. 1996, 54, 361-363.

87. Endo, M.; Lewin, M. Flame retardancy of polypropylene by phosphorus-based additives, in: Proceedings of the 4th Conference on Recent Advances in Flame Retardancy of Polymeric Materials, Stamford, CT, 1993.

88. Lewin, M.; Endo, M. Intumescent systems for flame retarding of polypropylene, in: G.L. Nelson, Ed., Fire and Polymers, II: Materials and Tests for Hazard Prevention. ACS Symposium Series, Vol. 599. American Chemical Society, Washington, DC, 1995, pp. 91-108.

89. Lewin, M.; Endo, M. Catalysis of intumescent flame retardancy of polypropylene by metallic compounds. Polym. Adv. Technol. 2003, 14, 3-11.

90. Bourbigot, S.; Le Bras, M. Synergy in intumescence: overview of the use of zeolites, in: M. Le Bras, G. Camino, S. Bourbigot, and R. Delobel, Eds., Fire Retardancy of Polymers: The Use of Intumescence. Royal Society of Chemistry, London, 1998, pp. 222-235.

91. Le Bras, M.; Bourbigot, S. Fire retarded intumescent thermoplastic formulations, synergy and synergistic agents: review, in: M. Le Bras, G. Camino, S. Bourbigot, and R. Delobel, Eds., Fire Retardancy of Polymers: The Use of Intumescence. Royal Society of Chemistry, London, 1998, pp. 64-75. 
92. Morley, J.C. Flame retardants and smoke suppressants, in: E.J. Wickson, Ed., Handbook of Polyvinyl Chloride Formulating. Wiley, New York, 1993, pp. 551-577.

93. Myszak, E.A., Jr. Use of submicron inorganic flame retardants in polymeric systems, in: Proceedings of the 4th Conference on Recent Advances in Flame Retardancy of Polymeric Materials, Stamford, CT, 1993.

94. Innes, J.; Innes, A. Char forming flame retardants for polycarbonate, presented at the Fall Meeting of the American Fire Safety Counsel, Las Vegas, NV, 2004.

95. Pan, W.-H. (General Electric). U.S. Patent 5274017, 1993.

96. Stern, G.; Horacek, H. Nitrogen-containing compounds: a forgotten, newly reestablished group of halogen-free flame retardants, in: Proceedings of the 3rd Conference on Recent Advances in Flame Retardancy of Polymeric Materials, Stamford, CT, 1992.

97. Myszak, E.D., Jr.; Sobus, M.T. New generation of inorganic colloids for flame retardancy and UV stabilization of polymers, in: Proceedings of the 7th Conference on Recent Advances in Flame Retardancy of Polymeric Materials, Stamford, CT, 1996.

98. Okoshi, M.; Nishizawa, H. Flame retardancy of nanocomposites. Fire Mater. 2004, 28, 423-429.

99. Zhang, Q.; Tian, M.; Wu, Y.; Lin, G.; Zhang, L. Effect of particle size on the properties of $\mathrm{Mg}(\mathrm{OH})_{2}$-filled rubber composites. J. Appl. Polym. Sci. 2004, 94, 2341-2346.

100. Smith, T.H.F. An overview of the toxicological aspects of flame retardant chemicals, in: Proceedings of the 2nd Conference on Recent Advances in Flame Retardancy of Polymeric Materials, Stamford, CT, 1991.

101. Landry, S.; Tange, L.; Blomqvist, P.; Rosell, L.; Simonson, M.; Anderson, P. FireLCA model: furniture including polyurethane and textile as case study, in: Proceedings of API EXPO2004, Las Vegas, NV, 2004, pp. 133-143.

102. Markarin, J. Flame retardants: higher performance and wider product choice. Plast. Add. Compound. 2003, Nov.-Dec. pp. 32-36. 
